\title{
Nutritive value and meat quality of domestic cattle (Bos taurus), zubron (Bos taurus $\times$ Bison bonasus) and European bison (Bison bonasus) meat
}

\author{
Andrzej Łozicki ${ }^{1}$, Wanda Olech², Maria Dymnicka ${ }^{1}$, Tomasz Florowski ${ }^{3}$,ech Adamczak ${ }^{3}$, Ewa Arkuszewska ${ }^{1}$ Tomasz $^{2}$ \\ Niemiec $^{1}$ \\ ${ }^{1}$ Department of Animal Nutrition and Biotechnology, ${ }^{2}$ Department of Genetics and Animal Breeding, ${ }^{3}$ Department of Food \\ Technology, Warsaw University of Life Sciences-SGGW, Nowoursynowska 166 ST.02-787 Warsaw \\ e-mail: andrzej_lozicki@sggw.pl
}

\begin{abstract}
The objective of the experiment was to study the nutritive value and meat quality aspects of domestic cattle (Bos taurus), zubron (Bos taurus $\times$ Bison bonasus) and European bison (Bison bonasus) meat. The bulls and zubrons were fattened to $600-650 \mathrm{~kg}$ of body weight using the same feeding regimen. The European bison meat was from selective shooting of males. The meat was analysed for chemical composition, fatty acid composition, meat quality characteristics and thiobarbituric acid reactive substance (TBARS) value. Compared to beef, zubron and European bison meat had a lower content of crude fat, crude ash and a higher moisture content. The meat of the zubrons and European bison showed a lower content of saturated fatty acids and a higher content of polyunsaturated fatty acids compared to beef. The shear force of meat was highest for European bison meat and lowest for beef. Higher a* and $b^{*}$ colour parameters were established in European bison and zubron meat. The highest TBARS value was found in beef.
\end{abstract}

Key words: beef, zubron meat, European bison meat, nutritive value, meat quality

\section{Introduction}

The development of the European bison (Bison bonasus) population in Europe enables them to be used for semen and crossed with dairy or beef cattle (Bos taurus). Zubron are obtained as a result of such crossbreeding (Bos taurus $\times$ Bison bonasus). More extensive studies on the crossing of cattle with European bison were conducted in the 1980 s and this research is also carried out today. Zubron were found to be characterised by good adaptation to harsh environmental conditions, good feed conversion, and high rate of weight gain (Sumiński 1987, Gołębiewska 2013). However, the research published to date failed to evaluate zubron meat for nutritive and culinary value parameters. The increased crossing of dairy or beef cattle with European bison semen could be an interesting solution for breeders interested in new directions in livestock production while offering an alternative to beef.

Zubron meat could be attractive as alternative red meat. Other than its nutritive value, it will be essential to evaluate the parameters associated with culinary usefulness and consumer assessment and acceptance. Consumers assess meat for its colour, proportion of intramuscular fat, consistency, and aroma. The edible quality of meat is determined by its tenderness and palatability (Liu et al. 1996, Miller et al. 2001). In the case of beef, these characteristics are determined by the processing of meat, but also by an animal's breed, age, diet and preslaughter handling (Christensen et al. 2011).

The nutritive value of meat is determined by its chemical composition, in particular the content and composition of protein and intramuscular fat (IMF), as well as the content of minerals and vitamins. The biological and nutritive value of protein is highly influenced by the intramuscular connective tissue (IMCT) content. The proportion, structure, and composition of IMCT in meat depend on the type of evaluated muscle, animal's breed and age (Purslow 2005). The fat is analysed for its content in the meat and for composition of fatty acids. Beef fat has been perceived as a source of unhealthy saturated fatty acids that contribute to cardiovascular diseases (Ulbricht and Southgate 1991). Composition of fatty acids in meat can be modified to increase the content of desirable acids and decrease the content of undesirable acids by using specific feed combinations. It is observed that pasture feeding of cattle increases the unsaturated fatty acids content of meat compared to feeding based on conserved roughages, especially with large amounts of concentrate (Daley et al. 2010, Turner et al. 2014). The chemical composition of beef also depends on the genetic factor of breed (Christensen et al. 2011, Pesonen et al. 2013, Huuskonen et al. 2016).

Interspecies crosses with American bison (Bison bison) or European bison (Bison bonasus) could be an interesting solution for cattle. The research has shown that compared to beef, meat from American bison is lower in saturated fatty acids (SFA) and higher in polyunsaturated fatty acids (PUFAs) (Rule et al. 2002, McDaniel et al. 2013). 
However, there are no studies in the literature on the composition of fatty acids in the European bison meat. There are also no studies available to evaluate the dietetic value of meat from the zubron, a hybrid of the European bison and domestic cattle.

The objective of the study was to compare the nutritive value and selected quality traits of beef and zubron meat. Based on earlier observations (Rule et al. 2002, Haščík et al. 2011, McDaniel et al. 2013), which showed that the chemical composition of American bison and European bison meat is nutritionally more beneficial compared to beef, it was hypothesised that zubron meat would have a higher nutritive value than beef. As a point of reference for beef and zubron meat, we used European bison meat while realising the complexity of factors that determined its quality.

\section{Materials and methods}

Beef, zubron meat, and European bison meat were analysed for basic chemical composition, fatty acid composition, $\alpha$-tocopherol content, lipid oxidation and selected culinary quality characteristics.

All the procedures used in this study were approved by the Local Ethics Committee for Experiments on Animals.

\section{Animals}

The beef originated from 10 domestic cattle (Holstein-Friesian [HF] x Limousin) bulls and the Zubron meat was obtained from 9 zubron bulls produced as a result of inseminating HF cows with European bison semen. The insemination of the HF cows was performed using the semen of 5 Limousin bulls and 5 European bison bulls. The cattle and zubron bulls were fattened to a final body weight of 600-650 kg. The slaughter age of the animals was 17-19 months. The European bison meat came from 10 males subjected to selective shooting.

The cattle calves were subjected to the rearing regimen of colostrum feeding, followed by rearing on milk replacer, hay, and feed mixture for calves until 2-3 months of age. After the milk replacer removal from the diet, it was modified to include maize silage. The zubron calves were reared with their dams on pasture until 6-7 months of age.

Both cattle and zubron bulls were subjected to the same feeding regimen, which began when the animals were 6 to 7 months old. The animals were fed a total mixed ration (TMR) ad libitum, composed of maize silage, hay and concentrate. The composition and nutritive value of the fattening rations are presented in Table 1 . During the experiment the cattle and zubron were placed on the same farm but in different barns. The animals were kept in pens of 5 animals. Wheat straw was used as a bedding. The bulls had free access to water.

\begin{tabular}{|c|c|c|}
\hline Item & Cattle bulls & Zubron bulls \\
\hline Maize silage DM (dry matter) $\mathrm{g} \mathrm{kg}^{-1}$ & 460 & 470 \\
\hline Hay DM g kg-1 & 110 & 120 \\
\hline Concentrate $^{1} \mathrm{DM} \mathrm{g} \mathrm{kg}^{-1}$ & 430 & 410 \\
\hline \multicolumn{3}{|l|}{ Nutritive value $1 \mathrm{~kg}$ of DM } \\
\hline UFV & 1.01 & 0.99 \\
\hline PDIN, g & 97.5 & 96.3 \\
\hline PDIE, g & 93.4 & 92.8 \\
\hline Crude protein, g & 158.3 & 156.4 \\
\hline NDF, g & 421.2 & 428.7 \\
\hline Crude fat, $\mathrm{g}$ & 34.7 & 33.8 \\
\hline Crude ash, g & 47.6 & 46.4 \\
\hline
\end{tabular}

The natural food base of the European bison consisted of forage from forest clearings (a major part of their diet), browse, forest floor vegetation and tree bark in the summer; and grasses, leaves, shrubs, as well as supplemental hay and roots in the winter. 


\section{Experimental and analytical procedures}

The cattle bulls as well as the zubrons were slaughtered in commercial abattoirs, whereas the European bison were shot under natural conditions. Twenty-four hours postmortem, samples of meat (musculus semitendinosus) were collected for analysis from the half-carcasses of slaughtered animals. The samples to be used for the assessment of $\mathrm{pH}$, color parameters, water holding capacity and texture measurements were kept under cold storage conditions for another $48 \mathrm{~h}$ and analysed $72 \mathrm{~h}$ after slaughter. Cold storage was also applied to the samples that were determined for thiobarbituric acid reactive substance (TBARS) level 3 and 7 days after slaughter. The other samples, to be assayed for the proximate chemical composition, fatty acid profile and $\alpha$-tocopherol content, were packed in polyethylene bags and stored to two weeks at a temperature of $-20{ }^{\circ} \mathrm{C}$ until the analysis was carried out. Prior to the analyses the samples were thawed at cold condition $\left(4-6{ }^{\circ} \mathrm{C}\right)$.

The chemical composition of the feeds and muscle was determined according to AOAC (2005): moisture and dry matter by drying at $105^{\circ} \mathrm{C}$ to constant weight, crude ash by incineration at $550{ }^{\circ} \mathrm{C}$ for $6 \mathrm{~h}$, crude protein ( $\left.\mathrm{N} \times 6.25\right)$ by using the micro-Kjeldahl technique (Kjeltec System 1026 Distilling Unit, Foss Tecator, Sweden) and crude fat after extraction with petroleum ether by the Soxhlet method. Neutral detergent fibre (NDF) in feed was determined according to Van Soest et al. (1991). The NDF was expressed as the ash-free residue after extraction with boiling neutral solutions of sodium lauryl sulfate and EDTA in a Tecator apparatus.

For fatty acids profile analysis, lipids were extracted according to the method by Folch et al. (1957) and fatty acids were esterified following the standard AOAC method (2005). The fatty acids analysis was conducted using a TRACE GC ULTRA gas chromatograph (Thermo Electron Corporation) on a SUPELCOWAX'M 10 Capillary GC Column $(30 \mathrm{~m} \times 0.25 \mathrm{~mm} \times 0.25 \mu \mathrm{m})$ under the following conditions of the separation process: carrier gas - helium at a flow rate of $7.5 \mathrm{ml}^{-1} \mathrm{~min}$, injector temperature $220^{\circ} \mathrm{C}$, column temperature $190^{\circ} \mathrm{C}$ and then $220^{\circ} \mathrm{C}$ with increase $3{ }^{\circ} \mathrm{C} \mathrm{min}{ }^{-1}$, held there for $35 \mathrm{~min}$, and detector temperature $250^{\circ} \mathrm{C}$.

Atherogenic index were calculated as the content ratio of SFA/unsaturated FA using the following formula proposed by Ulbricht and Southgate (1991):

$$
\text { Atherogenic index }(A I)=[C 12: 0+4(C 14: 0)+(C 16: 0)] / \Sigma(\text { MUFA+PUFA) }
$$

Meat $\mathrm{pH}$ was measured in muscle tissue with a $\mathrm{CP}-411 \mathrm{pH}$ meter (Elmetron, Zabrze, Poland). For each sample, three measurements of $\mathrm{pH}$ were made in different locations, taking the mean value as the result of the measurement. Prior to measurement, the device was calibrated using $\mathrm{pH} 4.0$ and 7.0 buffers.

Meat colour parameters were measured on fresh section of the sample, 20 min after pigment oxygenation. Colour was measured in the CIE L*a*b* system using a Minolta CR-200 Chroma Meter (Konica Minolta, D65 lighting, $2^{\circ}$ observer, $8 \mathrm{~mm}$ aperture) calibrated to a standard white plate $\left(L^{*} 97.83, a^{*}-0.45, b^{*}+1.88\right)$. For each sample the colour parameters were measured six times in different parts of the section, assuming the mean value as the measurement result.

For the measurement of texture parameters, meat samples weighing around $500 \mathrm{~g}$ were placed in $3 \% \mathrm{NaCl}$ solution and cold stored $\left(4^{\circ} \mathrm{C}\right)$ for $24 \mathrm{~h}$. After removal from the brine, the samples were scalded in $85^{\circ} \mathrm{C}$ hot water until the internal temperature reached $72^{\circ} \mathrm{C}$ in the geometric centre. The thermally treated samples were allowed to cool under cold storage conditions $\left(4^{\circ} \mathrm{C}\right)$ for $24 \mathrm{~h}$. After this time, the samples were cut to analyse the texture parameters. The samples for shear force measurement were $1 \times 1 \mathrm{~cm}$ cubes cut along the muscle fibres. The samples for measurement of penetration force were $20 \mathrm{~mm}$ thick slices. Prior to analysis, the samples were treated to ensure a uniform temperature of $18^{\circ} \mathrm{C}$. Texture was measured using a Zwick 1120 test machine (Zwick, Ulm, Germany) with an initial force of $0.5 \mathrm{~N}$ and a testing speed of $50 \mathrm{~mm} / \mathrm{min}$. Shear force was measured with a Warner-Bratzler attachment fitted with a flat blade. The maximum force needed to shear the sample transversely across the muscle fibres was measured. Seven measurements were made for each sample, assuming the average values as a final result. Penetration force was measured with a flat plunger of $13 \mathrm{~mm}$ diameter. The maximum force needed to push the plunger at $50 \%$ of initial sample height was measured. The penetration was performed along the muscle fibres. Six measurements were conducted for each sample and the average value was taken as the final result.

To determine water holding capacity, a sample weighing around $300 \mathrm{~g}$ was ground to a particle size of $4.5 \mathrm{~mm}$ in a laboratory grinder (Mesko W-60/N, Skarżysko-Kamienna, Poland). A ground sample was mixed to ensure homogeneity and analysed for water holding capacity according to the Grau and Hamm (1953) method. 
The quantitative determinations of $\alpha$-tocopherol were performed using HPLC conducted with electrochemical detection according to ESA - Application note. One gramme of tissue was homogenised and extracted with $5 \mathrm{ml}$ of a hexane:ethanol mixture (50:50) with the addition of $0.01 \%$ butylhydroxyanisole (BHA). The tocopherols were extracted by mixing in Vortex for $60 \mathrm{~min}$ in the dark at about $4{ }^{\circ} \mathrm{C}$ in hermetic vessels. The contents were then centrifuged in an Eppendorf 4250 centrifuge for $10 \mathrm{~min}$ at $11000 \mathrm{rpm}$ and at $4{ }^{\circ} \mathrm{C}$. Afterwards, the hexane phase was collected. The prepared sample $(1 \mathrm{ml})$ was evaporated under gaseous nitrogen atmosphere and the dry residue was dissolved in $200 \mu \mathrm{l}$ mobile phase and then placed in an auto-sampler's carrousel at $4{ }^{\circ} \mathrm{C}$.

Malondialdehyde, the most abundant product of all lipid peroxidation products, was measured using thiobarbituric acid according to the Uchiyama and Mihara (1978) method. The absorbance was measured at the wavelength of $535 \mathrm{~nm}$ with a Tecan Infinite M200 analyser (Tecan Group Ltd., Männedorf Switzerland). The results represent the concentration of thiobarbituric acid reactive substances in the samples $\left(\mathrm{nmol} \mathrm{g}^{-1}\right)$. The meat tissue was homogenised in $1 \%$ potassium chloride and centrifuged at $2000 \times \mathrm{g}$ for $15 \mathrm{~min}$ at $4{ }^{\circ} \mathrm{C}$. The supernatant was used for the analysis and the tissues were placed in the reaction solution ( $1 \%$ phosphoric acid, $2 \%$ butylated hydroxytoluene, $1 \%$ potassium chloride and $0.4 \%$ TBA). The solution was heated at $95{ }^{\circ} \mathrm{C}$ for 60 min prior to the analysis.

\section{Statistical analyses}

Statistical analyses were performed with IBM SPSS Statistics 21 for Windows. Before testing for group differences, normality of the data distribution was assessed in the groups using the Shapiro-Wilk test. Subsequently, the Kruskal-Wallis test was used to determine significant differences between the experimental groups. $p$-value of 0.05 or lower was considered to indicate statistical significance. The results in the table are presented as mean \pm standard deviation (SD).

\section{Results \\ Chemical composition of meat}

The meat of the European bison and zubron was characterised by significantly lower content of crude ash $(p \leq 0.05)$ and crude fat $(p \leq 0.01)$ and higher moisture $(p \leq 0.05)$ compared to beef (Table 2$)$. The zubron meat was characterised by a higher content of crude fat $(p \leq 0.01)$ compared to the European bison $(p \leq 0.01)$. No differences were found for crude protein content.

Table 2. Chemical composition of musculus semitendinosus muscle

\begin{tabular}{|c|c|c|c|c|}
\hline Item & Beef & European bison & Zubron & $p$-value \\
\hline Moisture, $\mathrm{g} \mathrm{kg}^{-1}$ & $736.48^{b} \pm 14.82$ & $754.89^{a} \pm 12.86$ & $751.62^{\mathrm{a}} \pm 13.01$ & $\leq 0.05$ \\
\hline Crude protein, $\mathrm{g} \mathrm{kg}^{-1}$ & $218.69 \pm 6.44$ & $211.40 \pm 7.88$ & $209.74 \pm 7.04$ & ns \\
\hline Crude fat, $\mathrm{g} \mathrm{kg}^{-1}$ & $21.25^{A} \pm 3.30$ & $11.27^{\mathrm{BD}} \pm 2.61$ & $15.57^{\mathrm{BC}} \pm 2.95$ & $\leq 0.01$ \\
\hline
\end{tabular}

\section{Fatty acid composition}

The total SFA content was significantly lower in zubron and European bison meat compared to beef $(p \leq 0.01)$ (Table 3). The beef showed significantly higher content of MUFA compared to the European bison meat $(p \leq 0.05)$. No differences were found for MUFA between the zubron meat and beef. Zubron and European bison meat was characterised by a significantly higher content of PUFAs, including $n-3$ and $n-6$ acids, compared to beef $(p \leq 0.01)$. European bison meat had a lower $n-6 / n-3$ ratio $(p \leq 0.01)$ compared to beef.

When analysing the proportion of different SFA, beef showed the significantly highest content of C14:0 and C16:0, while European bison meat the lowest ( $p \leq 0.01$ ) (Table 3). The proportion of $\mathrm{C20:0}$ and $\mathrm{C22:0}$ was similar in zubron meat and beef, but significantly lower than in European bison meat $(p \leq 0.01)$. 
Table 3. Fatty acid profile and atherogenic index of raw musculus semitendinosus

\begin{tabular}{|c|c|c|c|c|}
\hline Item & Beef & European bison & Zubron & $p$-value \\
\hline & \multicolumn{3}{|c|}{$\%$ of total fatty acids } & \\
\hline Total SFA & $43.8^{B} \pm 2.53$ & $32.4^{\mathrm{A}} \pm 5.61$ & $37.1^{\mathrm{A}} \pm 5.21$ & $\leq 0.001$ \\
\hline $\mathrm{C} 14: 0$ & $2.86^{\mathrm{BD}} \pm 0.71$ & $1.07^{A} \pm 0.39$ & $1.62^{\mathrm{BC}} \pm 0.39$ & $\leq 0.001$ \\
\hline C15:0 & $0.42 \pm 0.22$ & $0.33 \pm 0.22$ & $0.36 \pm 0.10$ & NS \\
\hline C16:0 & $26.8^{\mathrm{BD}} \pm 0.53$ & $14.9^{A} \pm 2.96$ & $18.43^{\mathrm{BC}} \pm 1.77$ & $\leq 0.001$ \\
\hline C17:0 & $0.83 \pm 0.08$ & $0.86 \pm 0.23$ & $0.79 \pm 0.30$ & NS \\
\hline C18:0 & $12.7 \pm 1.74$ & $14.0 \pm 2.86$ & $15.5 \pm 4.14$ & NS \\
\hline C20:0 & $0.11^{A} \pm 0.03$ & $0.31^{B} \pm 0.21$ & $0.14^{\mathrm{A}} \pm 0.10$ & $\leq 0.01$ \\
\hline C 22:0 & $0.06^{A} \pm 0.04$ & $0.93^{B} \pm 0.43$ & $0.23^{A} \pm 0.42$ & $\leq 0.001$ \\
\hline Total MUFA & $47.8^{b} \pm 3.48$ & $39.5^{a} \pm 0.95$ & $43.2^{\mathrm{ab}} \pm 8.07$ & $\leq 0.05$ \\
\hline C14:1 & $0.80^{B} \pm 0.31$ & $0.16^{A} \pm 0.07$ & $0.34^{\mathrm{A}} \pm 0.17$ & $\leq 0.001$ \\
\hline C15:1 & $0.30^{B} \pm 0.12$ & $0.36^{B} \pm 0.17$ & $0.08^{A} \pm 0.13$ & $\leq 0.01$ \\
\hline C16:1c9 & $3.64^{c} \pm 0.81$ & $1.54^{\mathrm{A}} \pm 0.60$ & $2.63^{B} \pm 1.05$ & $\leq 0.001$ \\
\hline C17:1 & $0.53 \pm 0.25$ & $0.51 \pm 0.13$ & $0.57 \pm 0.13$ & NS \\
\hline C18:1c9 & $39.6 \pm 2.28$ & $33.5 \pm 9.47$ & $36.3 \pm 7.58$ & NS \\
\hline $\mathrm{C} 18: 1 \mathrm{c} 11$ & $1.49 \pm 0.23$ & $1.58 \pm 0.41$ & $1.53 \pm 0.46$ & NS \\
\hline C18:1tr11 & $1.16^{a} \pm 0.05$ & $1.56^{b} \pm 0.35$ & $1.47^{\mathrm{ab}} \pm 0.45$ & $\leq 0.05$ \\
\hline C20:1c11 & $0.20^{B} \pm 0.04$ & $0.29^{c} \pm 0.08$ & $0.07^{A} \pm 0.12$ & $\leq 0.001$ \\
\hline Total PUFA & $4.78^{A} \pm 2.29$ & $19.5^{B} \pm 9.25$ & $17.5^{\mathrm{B}} \pm 7.83$ & $\leq 0.001$ \\
\hline C18:2c9tr11 CLA & $0.37^{A} \pm 0.12$ & $1.06^{B} \pm 0.60$ & $0.88^{B} \pm 0.48$ & $\leq 0.01$ \\
\hline $\mathrm{C} 18: 2 \mathrm{n} 6$ & $2.53^{\mathrm{A}} \pm 1.43$ & $7.10^{B} \pm 3.27$ & $8.58^{B} \pm 3.72$ & $\leq 0.001$ \\
\hline $\mathrm{C} 18: 3 \mathrm{n} 6$ & $0.14 \pm 0.03$ & $0.13 \pm 0.04$ & $0.12 \pm 0.06$ & NS \\
\hline C18:3 n3 & $0.29^{A} \pm 0.09$ & $0.57^{A} \pm 0.43$ & $1.23^{\mathrm{B}} \pm 0.65$ & $\leq 0.01$ \\
\hline $\mathrm{C} 20: 3 \mathrm{n} 6$ & $0.05^{A} \pm 0.03$ & $0.09^{A} \pm 0.06$ & $0.34^{B} \pm 0.32$ & $\leq 0.01$ \\
\hline $\mathrm{C} 20: 3 \mathrm{n} 3$ & $0.15^{\mathrm{ab}} \pm 0.08$ & $0.26^{\mathrm{b}} \pm 0.19$ & $0.08^{a} \pm 0.16$ & $\leq 0.05$ \\
\hline C20:4 n6 & $0.62^{\mathrm{A}} \pm 0.47$ & $3.72^{\mathrm{B}} \pm 2.63$ & $3.57^{B} \pm 2.45$ & $\leq 0.01$ \\
\hline $\mathrm{C} 20: 5 \mathrm{n} 3$ & $0.15^{A} \pm 0.10$ & $4.99^{B} \pm 4.19$ & $1.45^{\mathrm{A}} \pm 2.10$ & $\leq 0.01$ \\
\hline $\mathrm{C} 22: 4 \mathrm{n} 6$ & $0.09^{a} \pm 0.06$ & $0.23^{b} \pm 0.14$ & $0.15^{\mathrm{ab}} \pm 0.07$ & $\leq 0.05$ \\
\hline $\mathrm{C} 22: 5 \mathrm{n} 3$ & $0.18^{A} \pm 0.11$ & $0.76^{B} \pm 0.39$ & $0.86^{B} \pm 0.47$ & $\leq 0.001$ \\
\hline $\mathrm{C} 22: 6 \mathrm{n} 3$ & $0.02^{A} \pm 0.01$ & $0.25^{B} \pm 0.18$ & $0.28^{B} \pm 0.17$ & $\leq 0.01$ \\
\hline n3 PUFA & $0.79^{A} \pm 0.32$ & $6.83^{B} \pm 3.59$ & $4.80^{B} \pm 2.49$ & $\leq 0.001$ \\
\hline n6 PUFA & $3.62^{A} \pm 1.93$ & $11.6^{\mathrm{B}} \pm 5.91$ & $12.8^{B} \pm 6.17$ & $\leq 0.001$ \\
\hline n6/n3 PUFA & $4.52^{\mathrm{B}} \pm 1.13$ & $2.45^{A} \pm 1.90$ & $3.76^{\mathrm{AB}} \pm 1.19$ & $\leq 0.01$ \\
\hline Atherogenic index (AI) & $0.97^{\mathrm{B}} \pm 0.13$ & $0.56^{\mathrm{A}} \pm 0.13$ & $0.67^{A} \pm 0.17$ & $\leq 0.001$ \\
\hline
\end{tabular}

Values are reported as mean $\pm S D$ : cattle $n=10$, European bison $n=10$, zubron $n=9 ; A B, C D=$ differences within rows $(p \leq 0.01) ; a b=$ differences within rows $(p \leq 0.05)$

As regards MUFA, beef contained significantly more C14:1 than both European bison and zubron meat $(p \leq 0.01)$. The zubron meat contained less C15:1 compared to beef and European bison meat $(p \leq 0.01)$. C16:1 c9 was most abundant in beef $(p \leq 0.01)$. The proportion of this acid in zubron meat was also significantly higher compared to that in European bison meat ( $p \leq 0.01)$. Zubron meat contained the least C 20:1 c11 ( $p \leq 0.01)$. Differences in the content of this acid also occurred between beef and European bison meat, with a higher content in the latter $(p \leq 0.01)$. Compared to European bison meat, beef was also characterised by a lower content of $C 18: 1 \operatorname{tr} 11$. Compared to beef, both zubron and European bison meat had a higher content of C18:2 c9 tr 11 (CLA), C18:2 n6, $\mathrm{C} 20: 4 \mathrm{n} 6, \mathrm{C} 22: 5 \mathrm{n} 3$ and $\mathrm{C} 22: 6 \mathrm{n3}(p \leq 0.01)$. Compared to beef and European bison meat, zubron meat had a higher content of $\mathrm{C} 18: 3 \mathrm{n} 3$ and $\mathrm{C} 20: 3 \mathrm{n} 6$ ( $p \leq 0.01)$. The proportion of $\mathrm{C} 20: 3 \mathrm{n} 3$ was highest in European bison meat, with a significant difference compared to zubron meat $(p \leq 0.05)$. The lowest C 20:5 n3 content was in beef, but a significant difference occurred only in comparison with European bison meat. Also, C20:5 n3 content was significantly lower in zubron than in European bison meat $(p \leq 0.01)$. Most C22:4 n6 was found in European bison meat, in which it was significantly higher than in beef $(p \leq 0.05)$.

As a consequence of fatty acids composition, beef showed the highest atherogenic index (Al) ( $p \leq 0.01)$, in comparison with European bison and zubron meat.

\section{Intrinsic properties of the meat}

No significant differences were found in $\mathrm{pH}_{72}$ of the analysed beef, European bison and zubron meat (Table 4). Zubron meat was characterisized by significantly lower water holding capacity, compared to beef and European bison meat $(p \leq 0.01)$. 
Based on the analysis of meat colour parameters, no significant differences were found for lightness $\left(L^{*}\right)$. Beef showed the significantly lowest $a *$ and $b^{*}$ values $(p \leq 0.01)$ (Table 4$)$.

For texture parameters it was found that European bison and zubron meat was characterised by significantly higher shear force than beef $(p \leq 0.05$ ) (Table 4$)$. However, no significant differences were observed between the analysed meats in penetration force measurements.

Table 4. Selected parameters of meat quality

\begin{tabular}{|c|c|c|c|c|}
\hline Item & Beef & European bison & Zubron & $p$-value \\
\hline $\mathrm{pH}_{72 \mathrm{~h}}$ of meat & $5.68 \pm 0.087$ & $5.72 \pm 0.171$ & $5.61 \pm 0.124$ & ns \\
\hline $\begin{array}{l}\text { Water holding capacity of meat, } \\
\mathrm{cm}^{2} \mathrm{~g}^{-1}\end{array}$ & $19.26^{A} \pm 2.716$ & $20.93^{A} \pm 3.684$ & $26.12^{B} \pm 2.721$ & $\leq 0.01$ \\
\hline \multicolumn{5}{|l|}{ Meat colour } \\
\hline $\mathrm{L}^{*}$ & $34.59 \pm 1.336$ & $34.76 \pm 2.540$ & $33.02 \pm 1.403$ & ns \\
\hline$a^{*}$ & $19.63^{\mathrm{A}} \pm 1.311$ & $20.99^{B} \pm 1.337$ & $21.68^{B} \pm 1.049$ & $\leq 0.01$ \\
\hline$b^{*}$ & $-4.46^{A} \pm 0.747$ & $-2.11^{\mathrm{B}} \pm 0.067$ & $-2.94^{B} \pm 0.594$ & $\leq 0.01$ \\
\hline \multicolumn{5}{|l|}{ Meat texture } \\
\hline Shear force, $\mathrm{N} \mathrm{cm}^{2-1}$ & $105.82^{\mathrm{a}} \pm 41.48$ & $154.84^{b} \pm 51.43$ & $175.94^{b} \pm 38.26$ & $\leq 0.05$ \\
\hline Penetration force, $\mathrm{N}$ & $33.10 \pm 7.820$ & $39.09 \pm 11.24$ & $41.85 \pm 5.148$ & ns \\
\hline
\end{tabular}

Values are reported as mean \pm SD: cattle $n=10$, European bison $n=10$, zubron $n=9 ; A B=$ differences within rows $(p \leq 0.01)$; ab = differences within rows $(p \leq 0.05)$

\section{$\alpha$-tocopherol and indicators of fat oxidation}

No significant differences were found in $\alpha$-tocopherol content between beef and zubron meat, and between European bison meat and zubron meat (Table 5). The meat of European bison had a higher $\alpha$-tocopherol content compared to beef $(p \leq 0.05)$.

Differences were noted between the meats in the degree of lipid oxidation. At both measurements on $\mathrm{d} 3$ and 7 , the lowest TBARS was found in the European bison meat. It was significantly lower than in the beef, which was characterised by the highest level of fat oxidation $(p \leq 0.05)$. Also, the degree of lipid oxidation at both measurements was lower in the zubron meat compared to beef $(p \leq 0.05)$.

Table 5. Content of $\alpha$-tocopherol and TBARS value after cold storage of the meat

\begin{tabular}{|c|c|c|c|c|}
\hline Item & Beef & European bison & Zubron & $p$-value \\
\hline$\alpha$-tocopherol, $\mu \mathrm{g} \mathrm{g}^{-1}$ & $3.88^{b} \pm 0.285$ & $4.28^{a} \pm 0.417$ & $4.05^{a b} \pm 0.452$ & $\leq 0.05$ \\
\hline TBARS after 3 days, $\mathrm{nmol} \mathrm{g}^{-1}$ & $0.619^{b} \pm 0.121$ & $0.476^{\mathrm{a}} \pm 0.072$ & $0.527^{a} \pm 0.083$ & $\leq 0.05$ \\
\hline TBARS after 7 days, $\mathrm{nmol} \mathrm{g}^{-1}$ & $0.785^{b} \pm 0.141$ & $0.595^{\mathrm{a}} \pm 0.064$ & $0.645^{\mathrm{a}} \pm 0.081$ & $\leq 0.05$ \\
\hline
\end{tabular}

Values are reported as mean \pm SD: cattle $n=10$, European bison $n=10$, zubron $n=9$; ab = differences within rows $(p \leq 0.05)$

\section{Discussion}

\section{Chemical composition of the meat}

There are no detailed studies comparing the chemical composition of meat from European bison, and especially zubron with beef. Some information on the chemical composition of European bison meat is provided by Haščík et al. (2011), who investigated the chemical composition of $M$. longissimus dorsi in different age groups of European bison. The reported content of dry matter, crude protein and crude fat is similar to that in our study but is related to a different muscle. Unlike European bison and zubron, there are studies investigating the meat of American bison, which are closely related to European bison. Lower fat content in the American bison meat compared to beef was reported by McDaniel et al. (2013). The authors subjected American bison to a similar rearing and fattening regimen as this study's for zubrons: rearing on pasture forage was followed by feedlot fattening. 
This would suggest the differences in fat content may be genetically determined, as also indicated by the studies of Koch et al. (1995) and Rule et al. (2002). In the study by Koch et al. (1995), the meat from American bison and beef cattle crosses also had lower fat content compared to beef. Similar results were obtained in our study, where zubron meat was characterised by a lower fat content compared to beef.

\section{Fatty acid composition}

The present study showed differences in fatty acid composition between beef and European bison meat, and between beef and zubron meat. No studies have been conducted to date to compare the meat from these animal species for fatty acids.

The beef had a higher content of fat, a higher proportion of SFA and a lower proportion of PUFAs, including $n-3$ PUFAs. The differences found in the chemical composition can be genetically determined, as evidenced by the research with beef meat and meat from American bison which are closely related to European bison (Rule et al. 2002, McDaniel et al. 2013). These authors reported differences in the profile of fatty acids, including a lower proportion of SFA and a higher proportion of PUFAs and n-3 PUFAs in American bison meat. However, in the present study it can be assumed that despite the impact of the genetic factor, the observed differences were largely determined by the dietary factor. Pasture forage makes up the largest part of the diet of European bison, which is definitely an important factor increasing the proportion of unsaturated fatty acids in this meat.

Highly interesting are the results obtained for zubron meat in the study. The analysis of the composition of fatty acids showed that zubron and European bison meat contained significantly less SFA and over three times more PUFAs, including $n-3$ and $n-6$ acids, than in beef. The beneficial fatty acid composition of zubron meat could have also been affected by pasture feeding in the rearing phase. This is also supported by the studies of Smith et al. (2009). De Smet et al. (2004) point out the composition of fatty acids is also affected by the level of carcass fatness and by the content of intramuscular fat. As the fatness increases, the share of PUFAs in the acid profile decreases. In the present study, a greater content of the intramuscular fat was revealed in beef in comparison to zubron and European bison meat. It might have also been a factor determining the smaller PUFAs content in beef.

When comparing the fatty acid composition of zubron meat and beef, it is of particular importance to compare the content of these fatty acids, which can have a strongly negative or positive effect on the consumer's organism. Compared to zubron meat, beef contained significantly more saturated fatty acids C14:0 and C16:0, and these acids increase the total cholesterol (Ulbricht and Southage 1991, Willett 2012). Of nutritional importance is the fact that zubron and European bison meat has a higher PUFAs content compared to beef. The meat of European bison and zubrons, when compared to beef, was found to be significantly richer in n-6 PUFAs, including C18:2n6, which occurred in the highest amounts. These acids reduce the serum levels of total and LDL cholesterol (Willett 2012). European bison and zubron meat is also more abundant in n-3 PUFAs, which reduce the incidence of cardiovascular diseases, some types of cancer and allergies (Connor 1997). Another important acid in terms of its effect on the consumer is CLA (C18:2c9tr11). The largest amounts of CLA were found in the meat from European bison, which probably resulted from pasture forage being ingested by these animals. A comparison of the CLA content of beef and zubron meat revealed that it was over twice as high in the latter meat. Despite the similar combination of feeds administered in cattle and zubron diets during fattening, the higher CLA content of zubron meat could have also been affected by the genetic factor (De Smet et al. 2004). However, it appears that feeding forage prior to finishing with conserved feeds and concentrates had a more significant effect (Turner et al. 2014). It is also worth noting that the meat of European bison, but also of zubron meat, had an $n-6 / n-3$ fatty acid ratio below 4 . The recommended ratio for whole diet ranges between 4:1 and 1:1 (Daley et al. 2010).

In beef, that ratio surpassed 4 (4.52). However, other authors conducting studies on beef reported the $n-6 / n-3$ ratio to be lower than 4 (Huuskonen et al. 2016). The $n-6 / n-3$ acids ratio is largely determined by the feeding and increases along with the increase of concentrates in the rations (Daley et al. 2010, Pesonen et al. 2013). Pesonen et al. (2013) as well as Huuskonen et al. (2016) stated the breeds were also a factor determining the differences between $n-6$ and $n-3$ acids in meat. In the current study, the feeding regimen with both cattle and zubron was similar during the fattening, therefore the differences were the result of genetically conditioned factors.

The fact that beef differs from European bison and zubron meat in the content of saturated and unsaturated fatty acids that have the strongest effect on consumer results in differences between the meats in the atherogenic index (Al). The highest atherogenic index, most detrimental to consumer health was characteristic of beef. Similar to our study, McDaniel et al. (2013) found higher Al values for beef when comparing the Al of American bison meat and beef. 


\section{Intrinsic properties of the meat}

The mean $\mathrm{pH}$ of beef, European bison and zubron meat was in the 5.6-5.7 range, which corresponds to the values reported in the literature for good quality beef (Christensen et al. 2011). The water holding capacity is determined by environmental and genetic factors, the most important of which include ultimate $\mathrm{pH}$, rate of glycolysis and chilling rate (den Hertog-Meischke et al. 1997, Huff-Lonergan and Lonergan 2005). Because there were no differences in the $\mathrm{pH}_{72}$ of the meat, it can be concluded that the lower water holding capacity of zubron meat could result from a different rate of postmortem glycolysis.

Colour is one of the major quality traits of meat because it largely determines consumer acceptance (Liu et al. 1996, and Hunt 2005). This trait is considerably influenced by the level of myoglobin in meat, which determines its red colour. The meat myoglobin content is affected by breed and age of animal as well as their physical activity. In our study, the highest activity was displayed by European bison that live in the wild. That is probably why their meat was characterised by the higher proportion of redness $\left(a^{*}\right)$. Cattle and zubron were fattened indoors and they had restricted freedom of movement. However, the zubron were more active as they were reared with their mothers on pasture. The colour of meat deteriorates when myoglobin is oxidised to metmyoglobin (Liu et al. 1996). Myoglobin oxidation is correlated with the oxidation of fatty acids. The increase in the degree of lipid oxidation may be associated with poorer meat colour stability and thus its deterioration (Arnold et al. 1993, Wood and Enser 1997). In our study, the highest degree of lipid oxidation was found for beef, which was also characterised by the lowest red colour intensity. Brewer et al. (2001) show that colour lightness ( $\left.L^{*}\right)$ is most strongly correlated with the visual appraisal of meat. The $a^{*}$ value is largely determined by the content of heme pigments in meat and the degree of its oxidation (Mancini and Hunt 2005, Waritthitham et al. 2010) whereas redox potential and intramuscular fat content have an effect on $b *$ value (Mancini and Hunt 2005, Waritthitham et al. 2010). This is confirmed by our findings, where lower redness $\left(a^{*}\right)$ intensity was observed for beef with the highest degree of lipid oxidation. Beef showed the lowest intensity of yellowness ( $\left.b^{*}\right)$, which could be due to the highest content of intramuscular fat and the highest degree of lipid oxidation. Xie et al. (2012), who compared meat colour parameters in different breeds, found that they did not differ in $\mathrm{L}^{*}$ and $\mathrm{a}^{*}$ values. These parameters were similar to ours but there were differences in $b^{*}$ value. In the current study it is difficult to explain the differences in the colour intensity of $a^{*}$ and $b^{*}$ between beef and zubron meat. In the fattening period the animals were kept in similar conditions, with similar possibility of physical activity. The observed differences might therefore be the result of a greater content of intramuscular fat in beef and its higher oxidation.

Shear force and penetration force are indicators of meat tenderness, which is the most important quality trait in the mouthfeel assessment of meat by consumers. The penetration force was measured along the muscle fibres, and the results obtained were significantly influenced by the fact that the fibres were 'interrelated' within the muscles. When shear force was measured transversely across the muscle fibres, fibre thickness and IMCT content had greater importance. The present studies confirmed a lower shear force for beef meat in comparison to zubron and European bison meat and might be conditioned by a number of factors. The studies conducted by Wheeler et al. (2005) and Shackelford et al. (1994) indicate there were breedconditioned differences in meat tenderness measured by its shear force. It might have been the result of several factors such as: the differences between the breeds in the intramuscular fat content, different calpastatine activity, or differences in the composition of IMCT (Harper 1999, Wheeler et al. 2005). Among factors determining the meat's tenderness, the age of the animal is of particular importance. The tenderness diminishes as the age of the fattened animal increases (Shorthose and Harris 1990, Purslow 2005). It is the result of for example the increase of the muscle fibres' diameter, or the increase of the insoluble collage fraction ratio in IMCT (Nishimura et al. 1996, Młynek et al. 2012). As the present study revealed, the biggest collage content, including its insoluble fraction, could appear in the European bison meat, this phenomenon being the result of the high in vivo muscle activity in European bison living in the wild. These animals were also older than cattle and zubron, an issue that could have also contributed to the higher insoluble collagen fraction content. Shear force, measured as an indicator of meat tenderness, is also affected by the fat content of meat. Higher fat content reduces shear force, as indicated by the studies of Shackelford et al. (1994) and Christensen et al. (2011). Also in the studies of Wheeler et al. (1996) as well as Pesonen et al. (2013), a lower shear force was observed with animals exhibiting a higher content of intramuscular fat. In the present study, the highest intramuscular fat content occurred in beef, which was also characterised by the lowest shear force. This confirms the above-cited studies and shows that beef is characterised by better tenderness compared to the meat of zubron and European bison. The differences in the intramuscular fat content between beef and zubron/European bison meat could, therefore, be among the vital factors determining the measured shear force. 


\section{$\alpha$-tocopherol and indicators of fat oxidation}

Higher $\alpha$-tocopherol content improves the dietetic value of meat but also increases its antioxidant stability (Lauzuric et al. 2005) and by limiting the oxidation of fatty acids in meat or by stabilising oxymyoglobin, $\alpha$-tocopherol improves such parameters as colour and aroma (Arnold et al. 1993). The content of $\alpha$-tocopherol in meat is influenced by its dietary intake and source (Realini et al. 2004). Both the fattened cattle and zubrons were fed similar roughages and concentrates and received the same vitamin-mineral mixture; therefore, the animals had a similar $\alpha$-tocopherol intake. The diet of the European bison was based on forage and its intake had an effect on the $\alpha$-tocopherol content of meat. Forage is a good source of $\alpha$-tocopherol and many studies reported increased vitamin E content in meat when animals were fed green forage (Daley et al. 2010, Łozicki et al. 2012).

Lipid oxidation is one of the major determinants of meat quality. It influences the colour, aroma, flavor and nutritive value of meat (Li and Liu 2012). The oxidation of fatty acids contributes to the formation of ketone compounds and aldehydes that have a negative effect on the aroma as well as the colour of meat (Liu et al. 1996, Jakobsen and Bertelsen 2000). Thus, the degree of fat oxidation is a very important parameter of meat evaluation. PUFA are particularly susceptible to oxidation (Johns et al. 1989). Their increased proportion in fat limits the oxidative stability of intramuscular fat (Luciano et al. 2011, Scollan et al. 2014). A natural component of meat that neutralises free radicals and limits the oxidation of lipids is $\alpha$-tocopherol. Realini et al. (2004) reported a stabilising effect of vitamin E on lipid oxidation as TBARS increased with time after slaughter. In our study, the highest TBARS concentration at both measurements was found in beef. It was characterised by lower proportion of PUFAs compared to the meat of European bison and zubron. However, the highest TBARS level in this meat may result from its highest fat content. The highest proportion of PUFAs was found in European bison meat, but this meat was characterised by the lowest fat content and highest content of $\alpha$-tocopherol, which prevents PUFA against oxidation. Compared to beef, the meat of zubron was also characterised by a higher proportion of PUFAs. However, it contained less fat and more $\alpha$-tocopherol. Both these factors could contribute to the lower TBARS value compared to beef.

\section{Conclusions}

The present study is the first to compare beef with the meat of zubron but also European bison in terms of their nutritive value and selected meat quality characteristics. The results showed that compared to beef, zubron meat had lower fat content and better composition of fatty acids. The meat of European bison and zubron was also characterised by lower TBARS values after cold storage. As regards the evaluated parameters of eating quality and sensory analysis, zubron and European bison meat were characterised by higher $a^{*}$ and $b^{*}$ colour values, which may contribute to better consumer acceptance. However, these meats were less tender than beef.

\section{Acknowledgements}

This study was supported by the Polish National Research Council grant NCN NN 311251637.

\section{References}

AOAC 2005. Association of Official Analytical Chemists, Official Methods of Analysis. 18th Edition by AOAC International, Revision II 2007, USA.

Arnold, R.N., Arp, S.C., Scheller, K.K., Williams, S.N. \& Schaefer, D.M. 1993. Tissue equilibration and subcellular-distribution of vitamin E relative to myoglobin and lipid oxidation in displayed beef. Journal of Animal Science 71: 105-118. https://doi. org/10.2527/1993.711105x

Brewer, M.S., Zhu, L.G., Bidner, B., Meisinger, D.J. \& McKeith, F.K. 2001. Measuring pork color: effects of bloom time, muscle, $\mathrm{pH}$ and relationship to instrumental parameters. Meat Science 57: 169-176. https://doi.org/10.1016/S0309-1740(00)00089-9

Connor, W.E. 1997. The beneficial effects of omega-3 fatty acids: cardiovascular disease and neurodevelopment. Current Opinion Lipidology 8: 1-3. https://doi.org/10.1097/00041433-199702000-00001

Christensen, M., Ertbjerg, P., Failla, S., Saudo, C., Richardson, R.I., Nute, G. R., Olleta, J. L., Panea, B., Albertí, P., Juárez, M., Hocquette, J.F. \& Williams, J.L. 2011. Relationship between collagen characteristics, lipid content and raw and cooked texture of meat from young bulls of fifteen European breeds. Meat Science 87: 61-65. https://doi.org/10.1016/j.meatsci.2010.09.003

Daley, C.A., Abbott, A., Doyle, P.S., Nader, G.A. \& Larson, S. 2010. A review of fatty acid profiles and antioxidant content in grassfed and grain-fed beef. Nutrition Journal 9: 1-12. https://doi.org/10.1186/1475-2891-9-10

den Hertog-Meischke, M.J.A., van Laack, R.J.L.M. \& Smulders, F.J.M. 1997. The water-holding capacity of fresh meat. Veterinary Quarterly 19: 175-81. https://doi.org/10.1080/01652176.1997.9694767

De Smet, S., Raes, K. \& Demeyer, D. 2004. Meat fatty acid composition as affected by fatness and genetic factors: a review. Animal Research 53: 81-98. https://doi.org/10.1051/animres:2004003 
Folch, J., Lees, M. \& Sloane-Stanley, G.H. 1957. A simple method for the isolation and purification of total lipids from animal tissues. Journal of Biological Chemistry 226: 497-509.

Gołębiewska, E. 2013. Analysis of the possibility of producing zubrons - hybrids of cattle (Bos taurus) and European bison (Bison bonasus). Doctoral dissertation. p. 62-75. (in Polish).

Grau, R. \& Hamm, R. 1953. Eine einfache methode zur bestimmung der wasserbindung im muskel. Naturwissenschaften 40: 2930. (in German). https://doi.org/10.1007/BF00595734

Harper, G.S. 1999. Trends in skeletal muscle biology and the understanding of toughness in beef. Australian Journal of Agricultural Research 50: 1105-1129. https://doi.org/10.1071/AR98191

Haščík, P., Müller, M., Pavelková, A., Kačániová, M., Čuboň, J., Benczová, E., Habánová, M., Mihok, M. \& Garlík, J. 2011. Chemical structure of European Bison Musculus longissimus dorsi at different stage of age. Potravinarstvo 5: 17-21.

Huff-Lonergan, E. \& Lonergan, S.M. 2005. Mechanisms of water-holding capacity of meat: The role of postmortem biochemical and structural changes. Meat Science 71: 194-204. https://doi.org/10.1016/j.meatsci.2005.04.022

Huuskonen, A., Pesonen, M., \& Honkavaara, M. 2016. Performance and meat quality of Nordic Red and Aberdeen Angus bulls offered faba bean or field pea based whole crop legume-cereal silages. Agricultural and Food Science 25: 1-12.

Jakobsen, M. \& Bertelsen, G. 2000. Colour stability and lipid oxidation of fresh beef. Development of a response surface model for predicting the effects of temperature, storage time, and modified atmosphere composition. Meat Science 54: 49-57. https://doi.org/10.1016/S0309-1740(99)00069-8

Johns, A.M., Birkinshaw, L.H. \& Ledward, D.A. 1989. Catalysts of lipid oxidation in meat products. Meat Science 25: $209-220$. https://doi.org/10.1016/0309-1740(89)90073-9

Koch, R.M., Jung, H.G., Crouse, J.D., Varel, V.H. \& Cundiff, L.V. 1995. Growth, digestive capability, carcass, and meat characteristics of Bison bison, Bos taurus, and Bos × Bison. Journal of Animal Science 73: 1271-1281. https://doi.org/10.2527/1995.7351271x

Lauzuric, S., De la Fuente, J., Diaz, M.T., Alvarez, I., Perez, C. \& Canegue, V. 2005. Effect of dietary supplementation of vitamin E on characteristics of lamb meat packed under modified atmosphere. Meat Science 70: 639-646. https://doi.org/10.1016/j. meatsci.2005.02.013

Liu, Q., Scheller, K.K., Arp, S.C., Schaefer, D.M. \& Williams, S.N. 1996. Titration of fresh meat color stability and malondialdehyde development with Holstein steers fed vitamin E-supplemented diets. Journal of Animal Science 74:106-116. https://doi. org/10.2527/1996.741106x

Li, Y.F. \& Liu, S.M. 2012. Reducing lipid peroxidation for improving colour stability of beef and lamb: on-farm considerations. Journal of the Science of Food and Agriculture 92: 719-726. https://doi.org/10.1002/jsfa.4715

Luciano, G., Moloney, A.P., Priolo, A., Röhrle, F.T., Vasta, V., Biondi, L., López-Andrés, P., Grasso, S. \& Monahan, F.J. 2011. Vitamin $E$ and polyunsaturated fatty acids in bovine muscle and the oxidative stability of beef from cattle receiving grass or concentratebased rations. Journal of Animal Science 89: 3759-3768. https://doi.org/10.2527/jas.2010-3795

Łozicki, A., Dymnicka, M., Arkuszewska, E. \& Pustkowiak, H. 2012. Effect of pasture or maize silage feeding on the nutritional value of beef. Annals of Animal Science 12: 81-93. https://doi.org/10.2478/v10220-012-0007-5

Mancini, R.A. \& Hunt, M.C. 2005. Current research in meat color. Meat Science 71: 100-121. https://doi.org/10.1016/j.meatsci.2005.03.003

McDaniel, J., Askew, W., Bennett, D., Mihalopoulos, J., Anantharaman, S., Fjeldstad, A.S., Rule, D.C., Nanjee, N.M., Ryan, A., Harris, R.A. \& Richardson, R.S. 2013. Bison meat has a lower atherogenic risk than beef in healthy men. Nutrition Research 33: $293-302$. https://doi.org/10.1016/j.nutres.2013.01.007

Miller, M.F., Carr, M.A., Ramsey, C.B., Crockett, K.L. \& Hoover, L.C. 2001. Consumer thresholds for establishing the value of beef tenderness. Journal of Animal Science 79: 3062-3068. https://doi.org/10.2527/2001.79123062x

Młynek, K., Dzido, A. \& Janiuk, I. 2012. Physicochemical characteristics of beef and muscle microstructure depending on giant fibres present therein. Food. Science. Technology. Quality. 80: 93-105

Nishimura, T., Ojima, K., Liu, A., Hattori, A. \& Takahashi, K. 1996. Structural changes in intramuscular connective tissue during development of bovine semitendinosus muscle. Tissue \& Cell 28: 527-536. https://doi.org/10.1016/S0040-8166(96)80055-3

Pesonen, M., Honkavaara, M., Kämäräinen, H., Tolonen, T., Jaakkola, M., Virtanen, V. \& Huuskonen, A. 2013. Effects of concentrate level and rapeseed meal supplementation on performance, carcass characteristics, meat quality and valuable cuts of Hereford and Charolais bulls offered grass silage-barley-based rations. Agricultural and Food Science 22: 151-167.

Purslow, P.P. 2005. Intramuscular connective tissue and its role in meat quality. Meat Science 70: 435-447. https://doi.org/10.1016/j. meatsci.2004.06.028

Realini, C.E., Duckett, S.K., Brito, G.W., Dalla Rizza, M. \& De Matos, D. 2004. Effect of pasture vs. concentrate feeding with or without antioxidants on carcass characteristics, fatty acid composition, and quality of Uruguayan beef. Meat Science 66: 567-577. https://doi.org/10.1016/S0309-1740(03)00160-8

Rule, D.C., Broughton, K.S., Shellito, S.M. \& Maiorano, G. 2002. Comparison of muscle fatty acid profiles and cholesterol concentrations of bison, beef cattle, elk and chicken. Journal of Animal Science 80: 1202-1211. https://doi.org/10.2527/2002.8051202x

Scollan, N.D., Dannenberger, D., Nuernberg, K., Richardson, I., MacKintosh, S., Hocquette, J.F. \& Moloney, A.P. 2014. Enhancing the nutritional and health value of beef lipids and their relationship with meat quality. Meat Science 97: 384-394. https://doi. org/10.1016/j.meatsci.2014.02.015

Shackelford, S.D., Koohmaraie, M., Cundiff, L.V., Gregory, K.E., Rohrer, G.A. \& Savell, J.W. 1994. Heritabilities and phenotypic and genetic correlations for bovine post rigor calpastatin activity, intramuscular fat content, Warner-Bratzler shear force, retail product yield, and growth rate. Journal of Animal Science 72: 857-863. https://doi.org/10.2527/1994.724857x 
Shorthose, W.R. \& Harris, P.V. 1990. Effect of animal age on the tenderness of selected beef muscles. Journal of Food Science 55 : 1-8. https://doi.org/10.1111/j.1365-2621.1990.tb06004.x

Smith, S.B., Gill, C.A., Lunt, D.K. \& Brooks, M.A. 2009. Regulation of fat and fatty acid composition in beef cattle. Asian-Australian Journal of Animal Sciences 22: 1225-1233. https://doi.org/10.5713/ajas.2009.r.10

Sumiński, E. 1987. Żubronie. Przeglqd hodowlany 5: 18-21. (in Polish).

Turner, T.D., Pilfold, J.L., Jensen, J., Prema, D., Donkor, K.K., Van Hamme, J.D., Cinel, B., Galbraith, J.K. \& Church, J.S. 2014. Fatty acid profiles of Western Canadian bison (Bison bison) meat. Journal of Food Research 3: 146-155. https://doi.org/10.5539/jfr.v3n6p146

Uchiyama, M. \& Mihara, M. 1978. Determination of malonaldehyde precursor in tissue by thiobarbituric acid test. Analytic Biochemistry 86: 271-278. https://doi.org/10.1016/0003-2697(78)90342-1

Ulbricht, T.L.V. \& Southgate, D.A.T. 1991. Coronary heart disease: seven dietary factor. The Lancet 338: 985-992. https://doi. org/10.1016/0140-6736(91)91846-M

Van Soest, P.J., Robertson, J.B. \& Lewis, B.A. 1991. Methods for dietary fibre, neutral detergent fibre and non-starch polysaccharides in relation to animal nutrition. Journal of Dairy Science 74: 3583-3597. https://doi.org/10.3168/jds.S0022-0302(91)78551-2

Waritthitham, A., Lambertz, C., Langholz, H.J., Wicke, M. \& Gauly, M. 2010. Assessment of beef production from Brahman $\times$ Thai native and Charolais $\times$ Thai native crossbred bulls slaughtered at different weights. II: Meat quality. Meat Science 85: 196-200. https://doi.org/10.1016/j.meatsci.2009.12.025

Wheeler, T.L., Cundiff, L.V., Shackelford, S.D. \& Koohmaraie, M. 2005. Characterization of biological types of cattle (Cycle VII): Carcass, yield, and longissimus palatability traits. Journal of Animal Science 83: 196-207. https://doi.org/10.2527/2005.831196x

Willett, W.C. 2012. Dietary fats and coronary heart disease. Journal of Internal Medicine 272: 13-24. https://doi.org/10.1111/ j.1365-2796.2012.02553.x

Wood, J.D. \& Enser, M. 1997. Factors influencing fatty acids in meat and the role of antioxidants in improving meat quality. British Journal of Nutrition 78, Suppl. 1: 49-60. https://doi.org/10.1079/BJN19970134

Xie, X., Meng, Q., Cui, Z. \& Ren, L. 2012. Effect of cattle breed on meat quality, muscle fiber characteristics, lipid oxidation and fatty acid in China. Asian-Australian Journal of Animal Sciences 25: 824-831. https://doi.org/10.5713/ajas.2011.11462 